Session 7-4

\title{
U.S. News Rankings of Engineering Programs in Institutions without Doctoral Programs in Engineering: A Six-Year Longitudinal Study
}

\author{
James B. Farison, Zhuocheng Yang \\ Department of Electrical and Computer Engineering \\ Baylor University
}

\begin{abstract}
One of the questions engineering educators are often asked by their various constituencies is "How does your program rank nationally?" For the subject group of engineering programs (those without doctoral programs in engineering at their institution), the highly publicized annual U.S. News rankings are often cited - or rationalized - depending on the most recent rankings. In the U.S. News survey, each respondent is asked to rate the listed programs from 5 (highest) to 1 (lowest). In this paper, the authors explore the temporal variability over the most recent six rating/ranking year periods of the U.S. News ratings and rankings of bachelor's degree programs in engineering in institutions that do not offer doctoral programs in engineering. Specifically, this paper explores the variation of these annual ratings and rankings from year to year, institution by institution (but without specific institutional identification, which is not the purpose of the paper) and provides graphical data that illustrates the amount and a discussion that indicates the reason for some of this variability.
\end{abstract}

\section{Introduction}

The current paper describes the methodology of the U.S. News ranking process, displays those annual rankings through sets of longitudinal (temporal) graphs over the most recent six rating/ranking year periods, and offers some statistical measures of the rating and ranking results over those six ratings and rankings. The results illustrate the considerable variability of these ratings and rankings of engineering programs from year to year. The method by which the rankings are determined is reviewed and, if one grants the premise that the quality of most baccalaureate programs in engineering does not vary significantly from year to year, then much of this annual variability could be attributed to that methodology. This perspective would seem to be important in the inferences, interpretations and judgments of the various constituencies that use these rankings. This is an observation rather than a criticism, as college program evaluation (and ranking) is a very complex and ultimately individual issue. However, the perspective provided by this study (a significant update and expansion of two prior studies ${ }^{1,2}$ ) could be very helpful to those seeking to use the annual U.S. News rankings of these programs and for others involved in engineering education.

\section{U.S. News Methodology and Self-Description}

The following self-description of this process is given by U.S. News ${ }^{3}$ for the most recent survey and report, labeled 2008, as posted on-line by U.S. News \& World Report on 8/17/2007: 


\section{"Methodology: Best Undergraduate Engineering Programs"}

"The U.S. News rankings of undergraduate programs accredited by the Accreditation Board for Engineering and Technology are based solely on the judgments of deans and senior faculty who rated each program they are familiar with on a scale from 1 (marginal) to 5 (distinguished). Engineering school deans and faculty members were surveyed in spring 2007. We have separate rankings for undergraduate engineering program at schools that offer doctoral degrees in engineering and at schools whose terminal degree in engineering is a bachelor's or master's. Research at the graduate level often influences the undergraduate curriculum, and schools with doctoral programs in engineering tend to offer the widest possible range of offerings. Students who prefer a program focused on undergraduates can consult the list of top programs at schools whose terminal degree is the bachelor's or master's. Fortyfive percent of those surveyed returned ratings of the group whose terminal degree in engineering is a bachelor's or master's; 59 percent did so for the doctoral group. We also asked for nominations of the best programs in specialty areas; those receiving the most mentions in each appear here. Schools offering any courses in that specialty are eligible to be ranked in that specialty."

As indicated, the survey conducted each spring (most recently, spring 2007) is used to generate the next year's rankings (currently, 2008 rankings). The ratings and the rankings are discussed, respectively, in the next two sections.

\section{Ratings}

On an integer scale of 5, 4, 3, 2, 1 (5 being highest), the ratings for each institution provided by respondents are averaged and rounded to the nearest one decimal. For the 2008 data, averaged rating (and ranking) values for the top 36 institutions are reported in a commercial document available from U.S. News. The ratings figures are recorded in Table 1 for the 36 institutions with engineering programs with the highest ratings in the 2008 report. Those ratings ranged from 4.5 to 3.0 on the 5 point scale, as shown in Table 1 . The new 2008 ratings by U.S. News, as well as those reported in the past five annual ratings (2003-2007), provide the ratings data for the most recent six years, 2003 through 2008, explored in this study. Institutional names are proprietary and are not used here, as Table 1 shows. Rather, for tracking purposes, programs are labeled with ranking identifiers. For example, there were five programs tied for eleventh ranking due to the same 3.4 rating in 2008, and are labeled as 11(A), 11(B), 11(C), 11(D) and 11(E) in Table 1 and throughout this study. No rating distinction is implied by those letters (as those programs were equally rated); the letters are purely identifiers.

The blanks in Table 1 for some institutions in some years mean that the program was not on the ranked programs' report for that year. Three institutions have that situation: 2008 Rank 20(E), 2008 Rank 25(C) and 2008 Rank 25 (D). Missing years could mean that the program did not reach the cut-off those years or, possibly, that it was not yet accredited or that it has been terminated. These gaps will be evident on the subsequent ratings and ranking graphs, as well. Those instances are one of the goals of this study, namely, the degree of consistency or variability of these ratings and rankings. The statistical data in the two rightmost columns of Table 1 are discussed following the discussion of the ratings and their graphical presentation in Figure 2 through Figure 9.

Proceedings of the 2008 ASEE Gulf-Southwest Annual Conference

The University of New Mexico - Albuquerque

Copyright ( ${ }^{2}$ 2008, American society for Engineering Education 
Table 1. U.S. News Best Undergraduate Engineering Program Ratings

\begin{tabular}{|c|c|c|c|c|c|c|c|c|}
\hline & 2003 & 2004 & 2005 & 2006 & 2007 & 2008 & Mean & STD1 \\
\hline 2008 Rank 1(A) & 4.3 & 4.2 & 4.2 & 4.3 & 4.4 & 4.5 & 4.32 & 0.12 \\
\hline 2008 Rank 1(B) & 4.5 & 4.4 & 4.4 & 4.5 & 4.4 & 4.5 & 4.45 & 0.05 \\
\hline 2008 Rank 3 & 4.0 & 4.0 & 4.1 & 4.0 & 4.0 & 4.2 & 4.05 & 0.08 \\
\hline 2008 Rank 4 & 3.5 & 3.6 & 3.7 & 3.9 & 3.9 & 4.0 & 3.77 & 0.20 \\
\hline 2008 Rank 5(A) & 3.8 & 3.7 & 3.9 & 3.9 & 4.0 & 3.9 & 3.87 & 0.10 \\
\hline 2008 Rank 5(B) & 3.7 & 3.7 & 3.9 & 3.9 & 4.0 & 3.9 & 3.85 & 0.12 \\
\hline 2008 Rank 7(A) & 3.6 & 3.5 & 3.6 & 3.6 & 3.7 & 3.8 & 3.63 & 0.10 \\
\hline 2008 Rank 7(B) & 3.8 & 3.6 & 3.7 & 3.8 & 3.7 & 3.8 & 3.73 & 0.08 \\
\hline 2008 Rank 9(A) & 3.3 & 3.3 & 3.3 & 3.4 & 3.5 & 3.6 & 3.40 & 0.13 \\
\hline 2008 Rank 9(B) & 3.3 & 3.3 & 3.4 & 3.4 & 3.5 & 3.6 & 3.42 & 0.12 \\
\hline 2008 Rank 11(A) & 3.3 & 3.2 & 3.2 & 3.5 & 3.3 & 3.4 & 3.32 & 0.12 \\
\hline 2008 Rank 11(B) & 3.2 & 3.2 & 3.3 & 3.2 & 3.3 & 3.4 & 3.27 & 0.08 \\
\hline 2008 Rank 11(C) & 3.3 & 3.3 & 3.2 & 3.4 & 3.5 & 3.4 & 3.35 & 0.10 \\
\hline 2008 Rank 11(D) & 3.3 & 3.3 & 3.3 & 3.5 & 3.3 & 3.4 & 3.35 & 0.08 \\
\hline 2008 Rank 11(E) & 3.2 & 3.1 & 3.3 & 3.2 & 3.2 & 3.4 & 3.23 & 0.10 \\
\hline 2008 Rank 16(A) & 3.2 & 3.3 & 3.2 & 3.2 & 3.2 & 3.3 & 3.23 & 0.05 \\
\hline 2008 Rank 16(B) & 2.8 & 2.9 & 3.0 & 2.9 & 3.1 & 3.3 & 3.00 & 0.18 \\
\hline 2008 Rank 16(C) & 3.2 & 3.2 & 3.2 & 3.2 & 3.3 & 3.3 & 3.23 & 0.05 \\
\hline 2008 Rank 16(D) & 3.3 & 3.2 & 3.0 & 3.1 & 3.1 & 3.3 & 3.17 & 0.12 \\
\hline 2008 Rank 20(A) & 3.1 & 3.1 & 3.2 & 3.1 & 3.1 & 3.2 & 3.13 & 0.05 \\
\hline 2008 Rank 20(B) & 3.1 & 3.2 & 3.0 & 3.0 & 3.1 & 3.2 & 3.10 & 0.09 \\
\hline 2008 Rank 20(C) & 3.1 & 3.0 & 3.0 & 3.2 & 3.2 & 3.2 & 3.12 & 0.10 \\
\hline 2008 Rank 20(D) & & & & 3.2 & 3.0 & 3.2 & & \\
\hline 2008 Rank 20(E) & 3.0 & 2.9 & 3.0 & 3.1 & 3.1 & 3.2 & 3.05 & 0.10 \\
\hline 2008 Rank 25(A) & 2.9 & 2.8 & 3.0 & 3.1 & 3.1 & 3.1 & 3.00 & 0.13 \\
\hline 2008 Rank 25(B) & 3.1 & 3.0 & 3.1 & 3.2 & 3.1 & 3.1 & 3.10 & 0.06 \\
\hline 2008 Rank 25(C) & & & & & 2.9 & 3.1 & & \\
\hline 2008 Rank 25(D) & & & & 3.1 & 3.2 & 3.1 & & \\
\hline 2008 Rank 25(E) & 2.9 & 2.7 & 2.9 & 2.9 & 3.0 & 3.1 & 2.92 & 0.13 \\
\hline 2008 Rank 25(F) & 3.1 & 3.0 & 3.1 & 3.1 & 2.9 & 3.1 & 3.05 & 0.08 \\
\hline 2008 Rank 31(A) & 2.8 & 2.8 & 2.8 & 2.9 & 2.9 & 3.0 & 2.87 & 0.08 \\
\hline 2008 Rank 31(B) & 2.9 & 2.9 & 2.9 & 3.0 & 3.0 & 3.0 & 2.95 & 0.05 \\
\hline 2008 Rank 31(C) & 2.7 & 3.0 & 3.0 & 2.9 & 3.0 & 3.0 & 2.93 & 0.12 \\
\hline 2008 Rank 31(D) & 3.0 & 2.9 & 2.7 & 3.0 & 3.0 & 3.0 & 2.93 & 0.12 \\
\hline 2008 Rank 31(E) & 3.0 & 2.9 & 3.0 & 3.1 & 3.1 & 3.0 & 3.02 & 0.08 \\
\hline 2008 Rank 31(F) & 2.8 & 2.8 & 2.8 & 2.9 & 3.0 & 3.0 & 2.88 & 0.10 \\
\hline 2008 Rank 31(G) & 3.0 & 3.1 & 3.0 & 3.1 & 3.1 & 3.0 & 3.05 & 0.05 \\
\hline
\end{tabular}


Table 1 provides the actual ratings numbers (and, also the rankings, which will be explored later) by the pseudo-naming of the respective programs. However, a graphical form may be a much more effective way to display the characteristics of the data. Accordingly, the 37 individual program ratings for 2008 from Table 1 are also shown graphically in Figure 1. This graph reflects the published ratings range from 4.5 to 3.0, noted previously. It also reflects the rating ties, appearing as horizontal segments due to their equal ratings. The "flattening" of the curve is a critical property of the data, and is explored further in the subsequent analysis.

Figure 1 and the subsequent Ratings graph groupings of programs in Figures 2-9 have a vertical scale that results in higher ratings appearing higher on the vertical scale. Specifically, Figures 29 provide that rating data graphically for the six years (2003, 2004, 2005, 2006, 2007 and 2008) for equally rated sets of these 37 programs, grouped according to the 2008 ratings, as follows:

$\begin{array}{lll}\text { Figure 2 } & \text { 2008 ratings of 4.5, 4.2 } & \text { 3 programs } \\ \text { Figure 3 } & \text { 2008 ratings of 4.0, 3.9 } & \text { 3 programs } \\ \text { Figure 4 } & \text { 2008 ratings of 3.8, 3.6 } & 4 \text { programs } \\ \text { Figure 5 } & \text { 2008 ratings of 3.4 } & 5 \text { programs } \\ \text { Figure 6 } & \text { 2008 ratings of 3.3 } & 4 \text { programs } \\ \text { Figure 7 } & \text { 2008 ratings of 3.2 } & 5 \text { programs } \\ \text { Figure 8 } & \text { 2008 ratings of 3.1 } & 6 \text { programs } \\ \text { Figure 9 } & \text { 2008 ratings of 3.0 } & 7 \text { programs }\end{array}$

Since only a single color is used for the connection between any two specific points from year to year, the individually colored lines representing different institutions may be lost. However, the set of distinct year marker symbols still provide uniqueness for the curves and data points.

Figure 2 shows that the two top-rated programs: a) have tied for the past two years, b) increased their rating by 0.1 point in the latest period, after being separated by 0.2 point for at least the previous four years, and c) have not varied by more than 0.1 point from one year to another, have varied in rating in all but one of the six years (but by no more than 0.1 point each per year). Further, even the modest 0.1 point rating change could be caused the rounding-off to one decimal in the ratings average calculation (i.e., a change from 4.44 to 4.45 in the calculated average would result in a rating change from 4.4 to 4.5). Notably, the third ranked program increased its rating by 0.2 point in the most recent ratings.

Figure 3 illustrates a rising and converging (but non-monotonic) pattern, with three programs separated by 0.3 point in 2003 coming to the same 3.9 point rating in 2006, before diverging again slightly in 2007 and 2008. Figure 3 also shows the remarkable monotonic non-decreasing rise from 3.5 to 4.0 over this six-year period. Figure 5 illustrates rather markedly the ups-anddowns of the individual program ratings, with one program increasing from 3.1 in 2004 to 3.4 in 2008 and another raising by 0.2 point one year and giving it back the next. Figure 6 shows the interesting cases of a program dropping by 0.3 point over three years, but also another program that increased rather dramatically by 0.5 point during this period. As the rating curve flattens (i.e., more programs at each 2008 rating), Figures 7-9 show some more complex graphical results. For example, the seven programs shown in Figure 9 that were rated at 3.0 in 2008 had previous ratings over this six-year period from 2.7 to 3.1 . 
Figure 1. 2008 Ratings

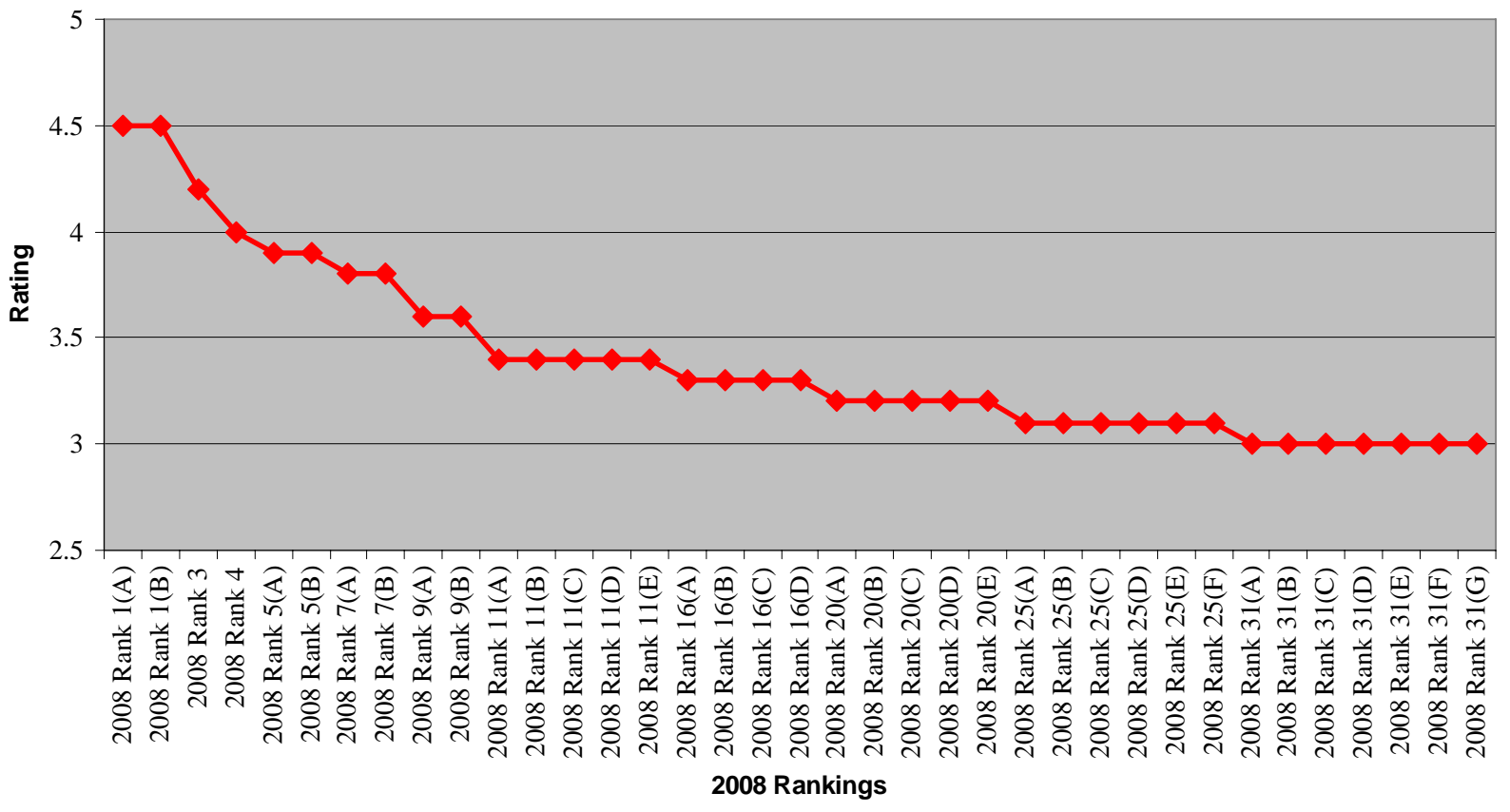

Figure 2. 2003-2008 Ratings (2008 Rank 1(A)-3)

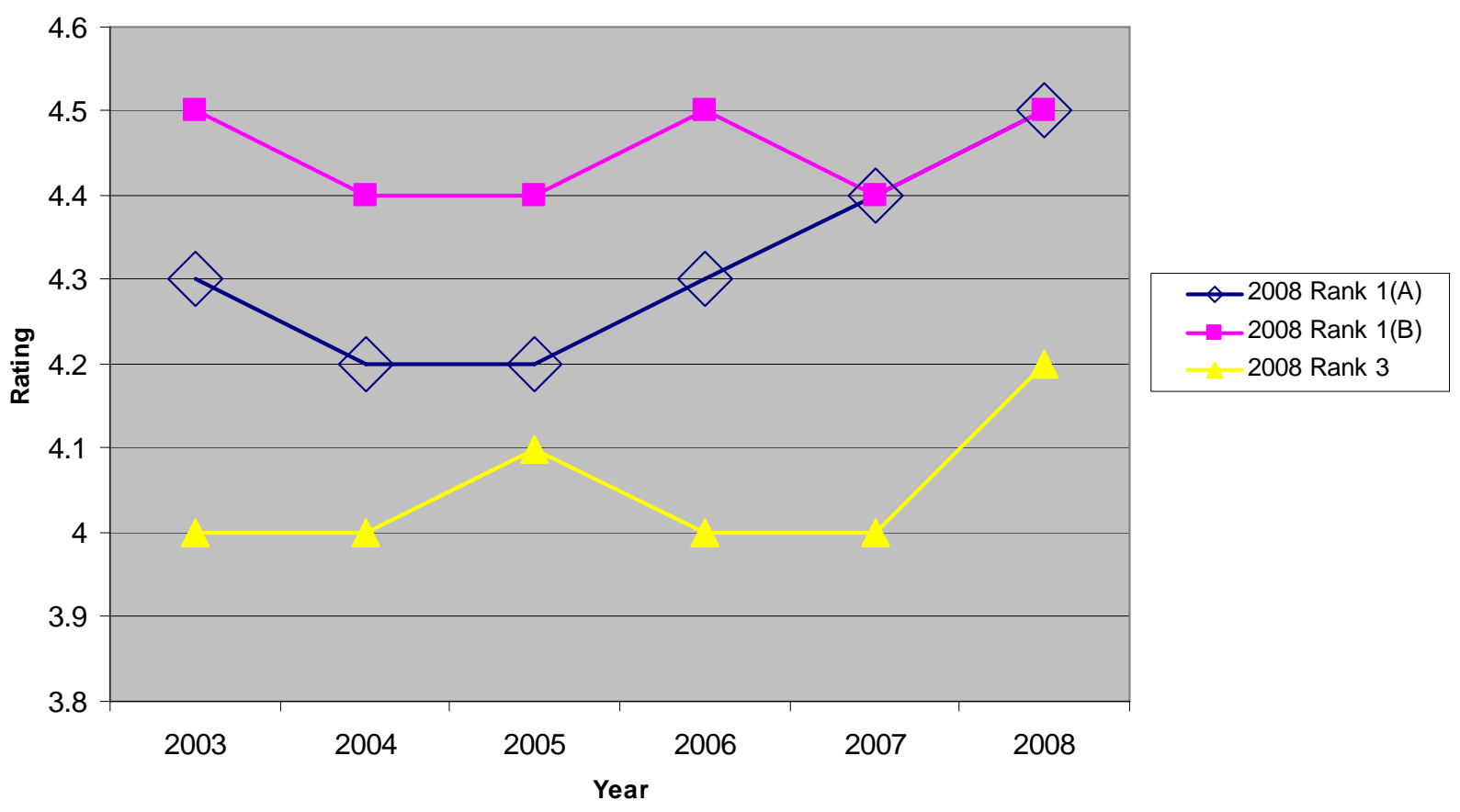

Proceedings of the 2008 ASEE Gulf-Southwest Annual Conference The University of New Mexico - Albuquerque

Copyright (c) 2008, American society for Engineering Education 
Figure 3. 2003-2008 Ratings (2008 Rank 4-5(B))
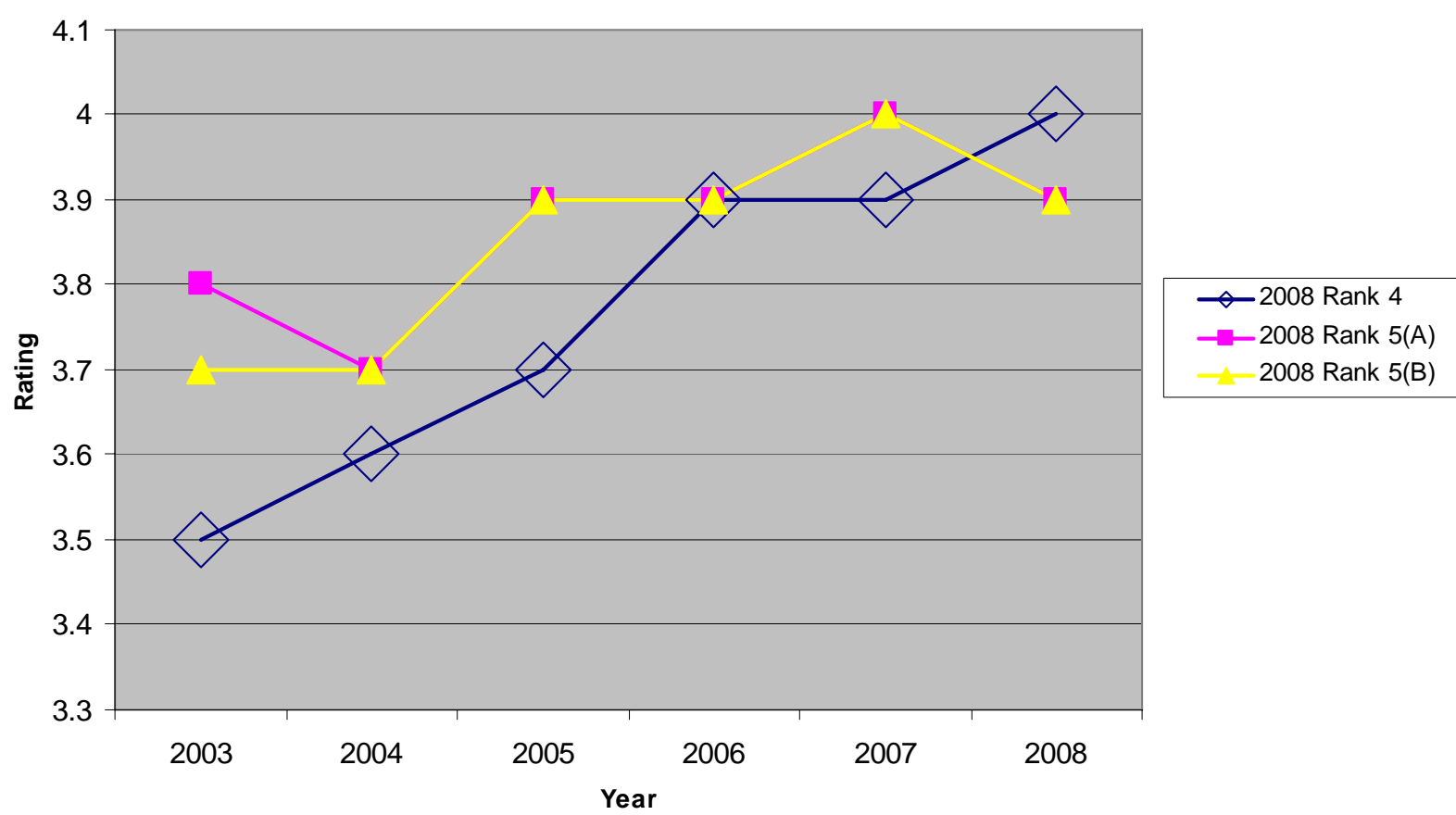

Figure 4. 2003-2008 Ratings (2008 Rank 7(A)-9(B))

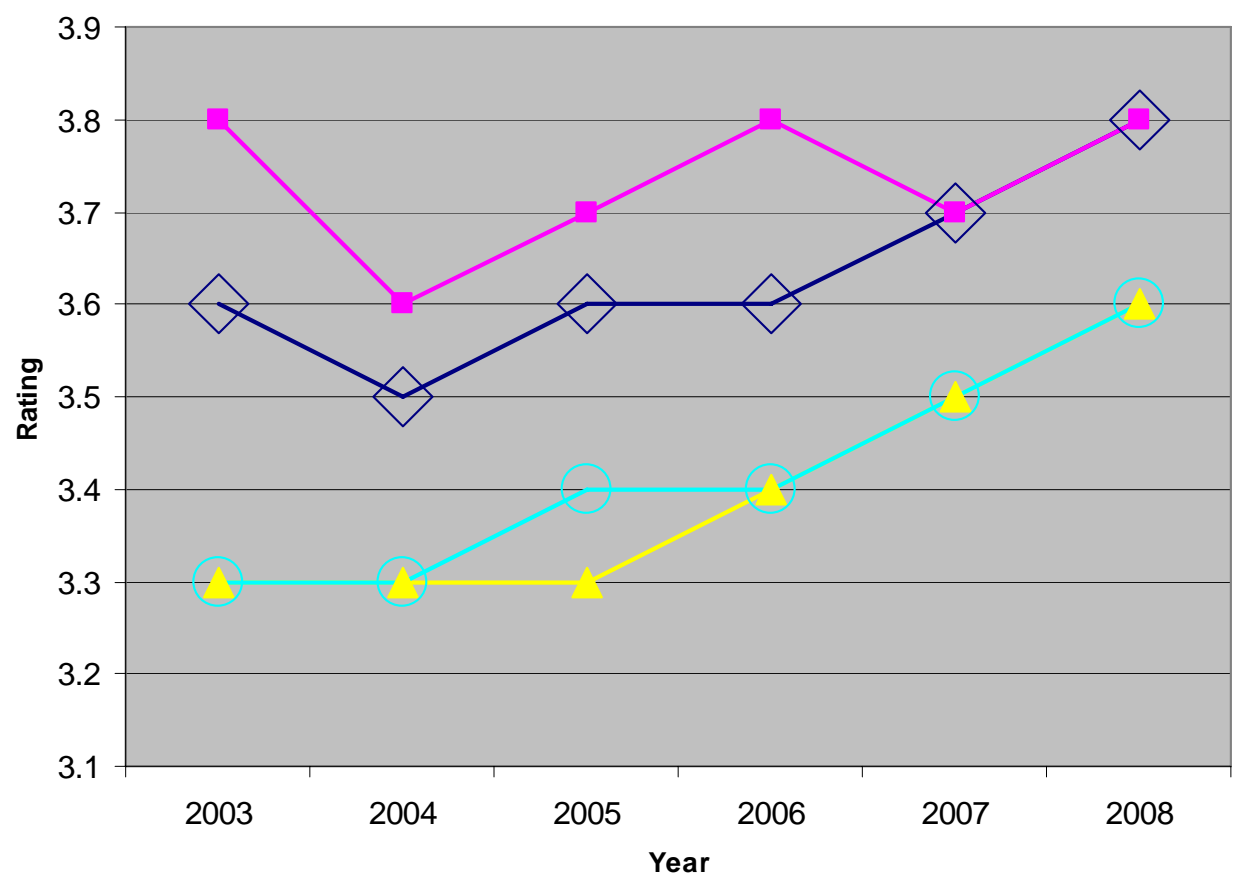


Figure 5. 2003-2008 Ratings (2008 Rank 11(A)-11(E))

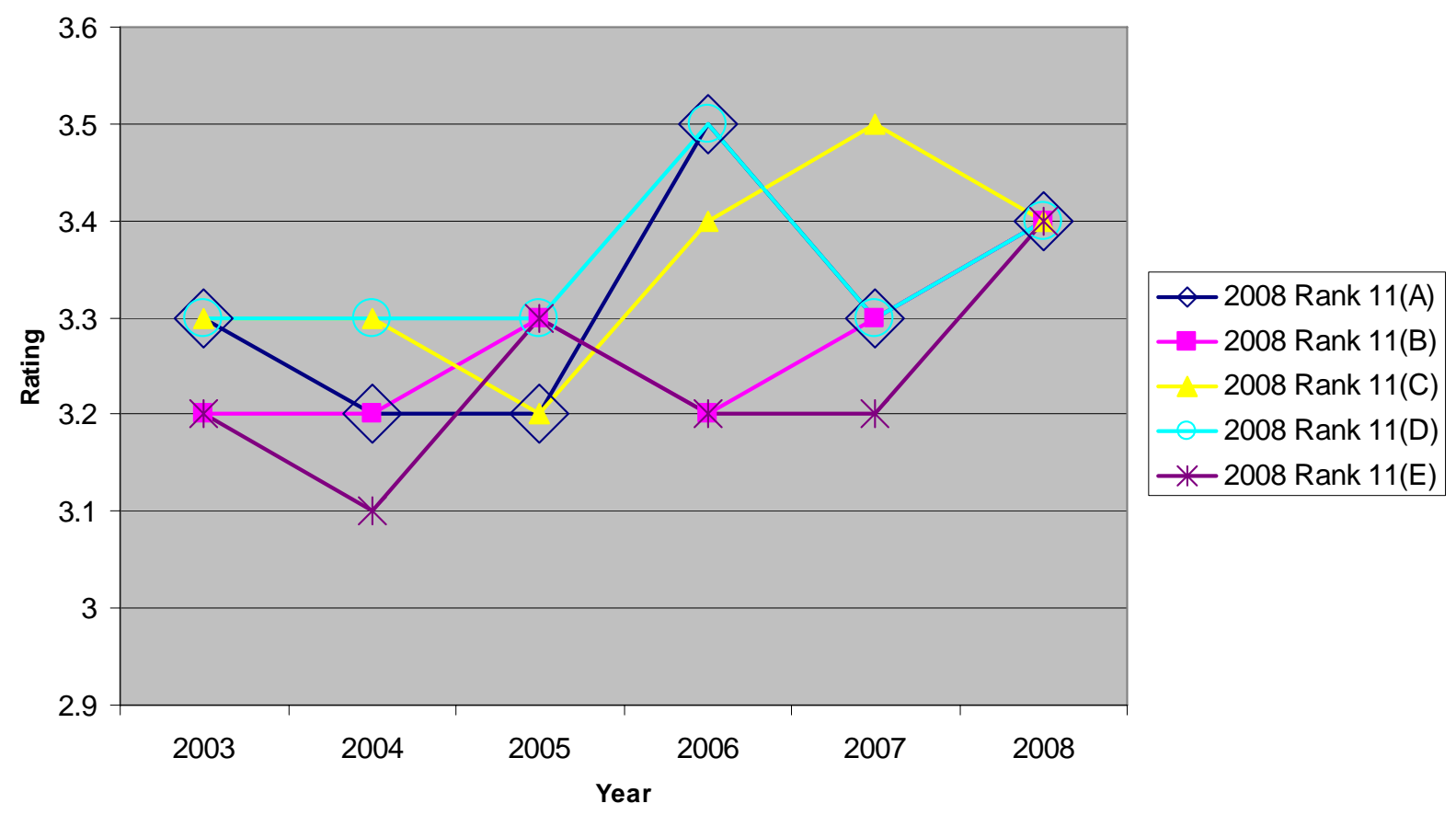

Figure 6. 2003-2008 Ratings (2008 Rank 16(A)-16(D))

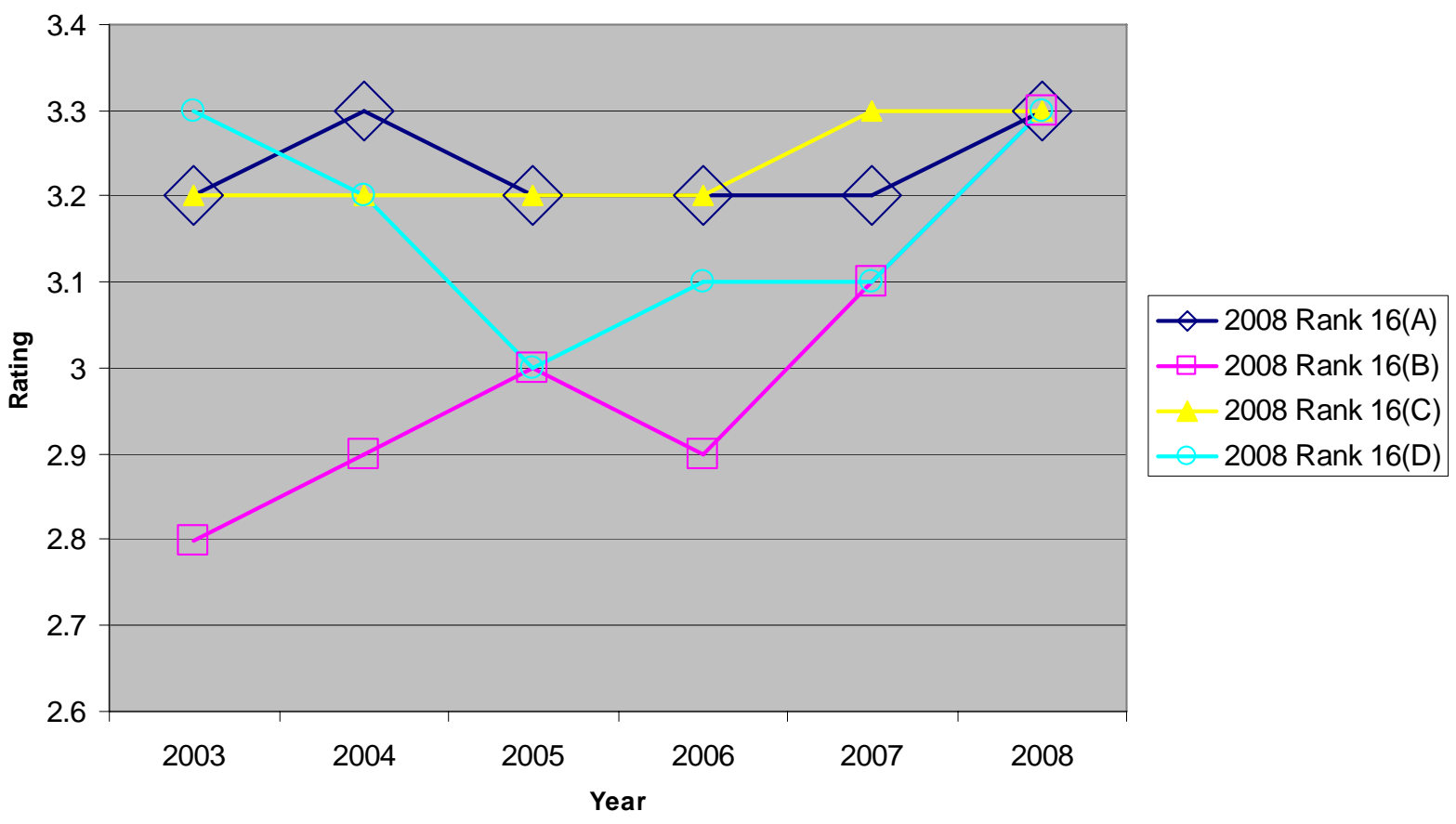

Proceedings of the 2008 ASEE Gulf-Southwest Annual Conference The University of New Mexico - Albuquerque

Copyright (c) 2008, American society for Engineering Education 
Figure 7. 2003-2008 Ratings (2008 Rank 20(A)-20(E))

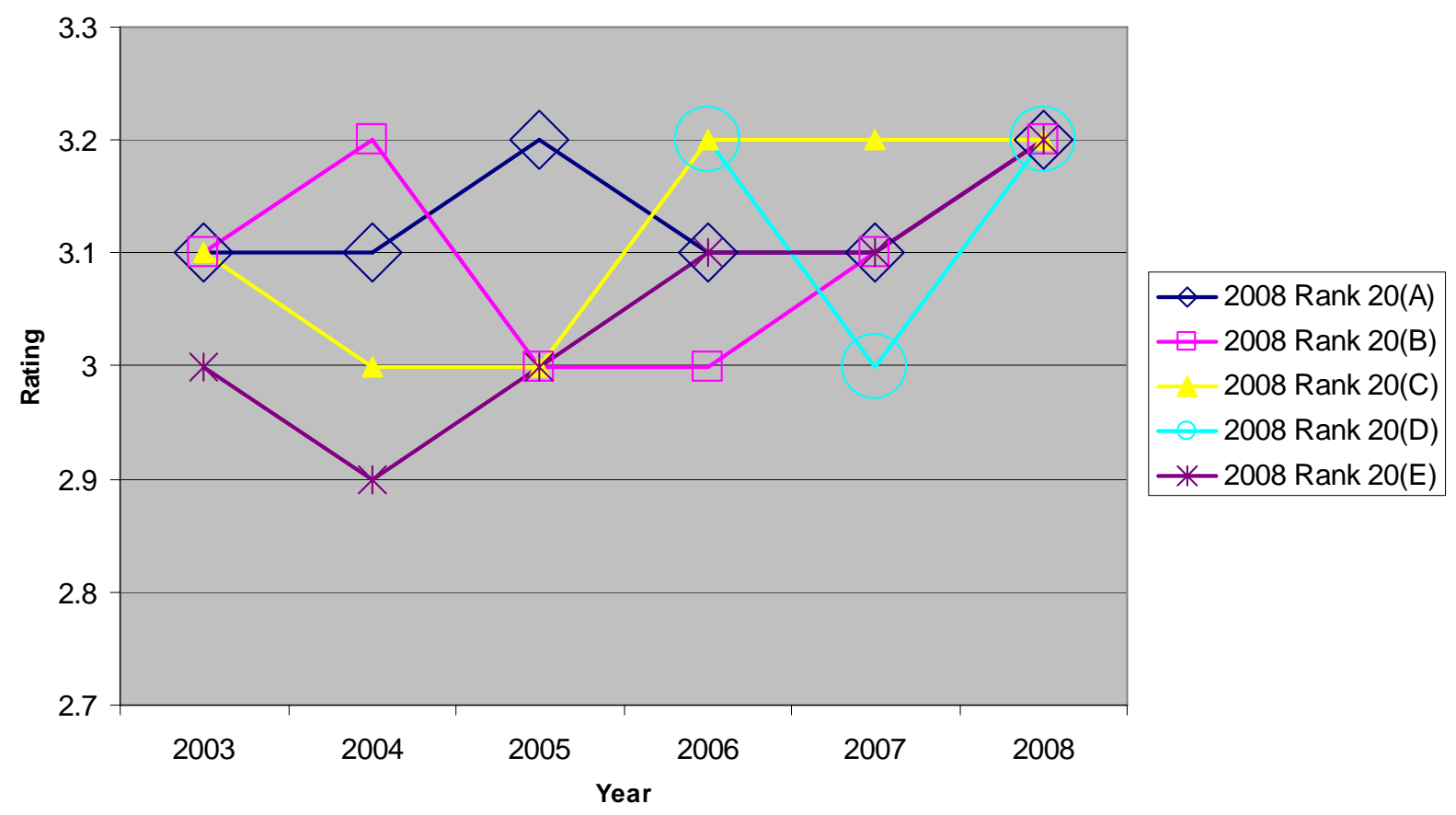

Figure 8. 2003-2008 Ratings (2008 Rank 25(A)-25(F))

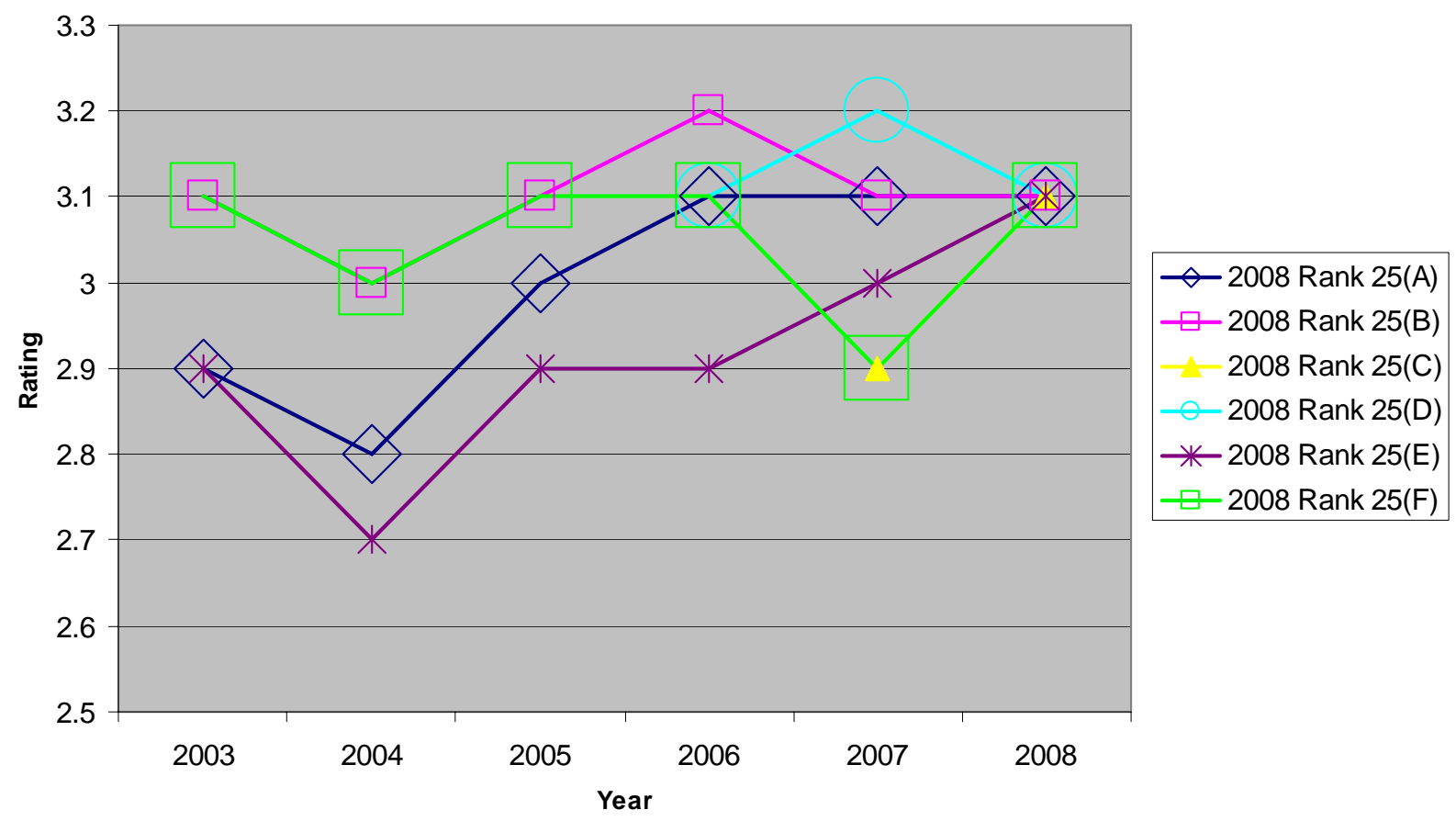

Proceedings of the 2008 ASEE Gulf-Southwest Annual Conference The University of New Mexico - Albuquerque

Copyright (c) 2008, American society for Engineering Education 
Figure 9. 2003-2008 Ratings (2008 Rank 31(A)-31(G))

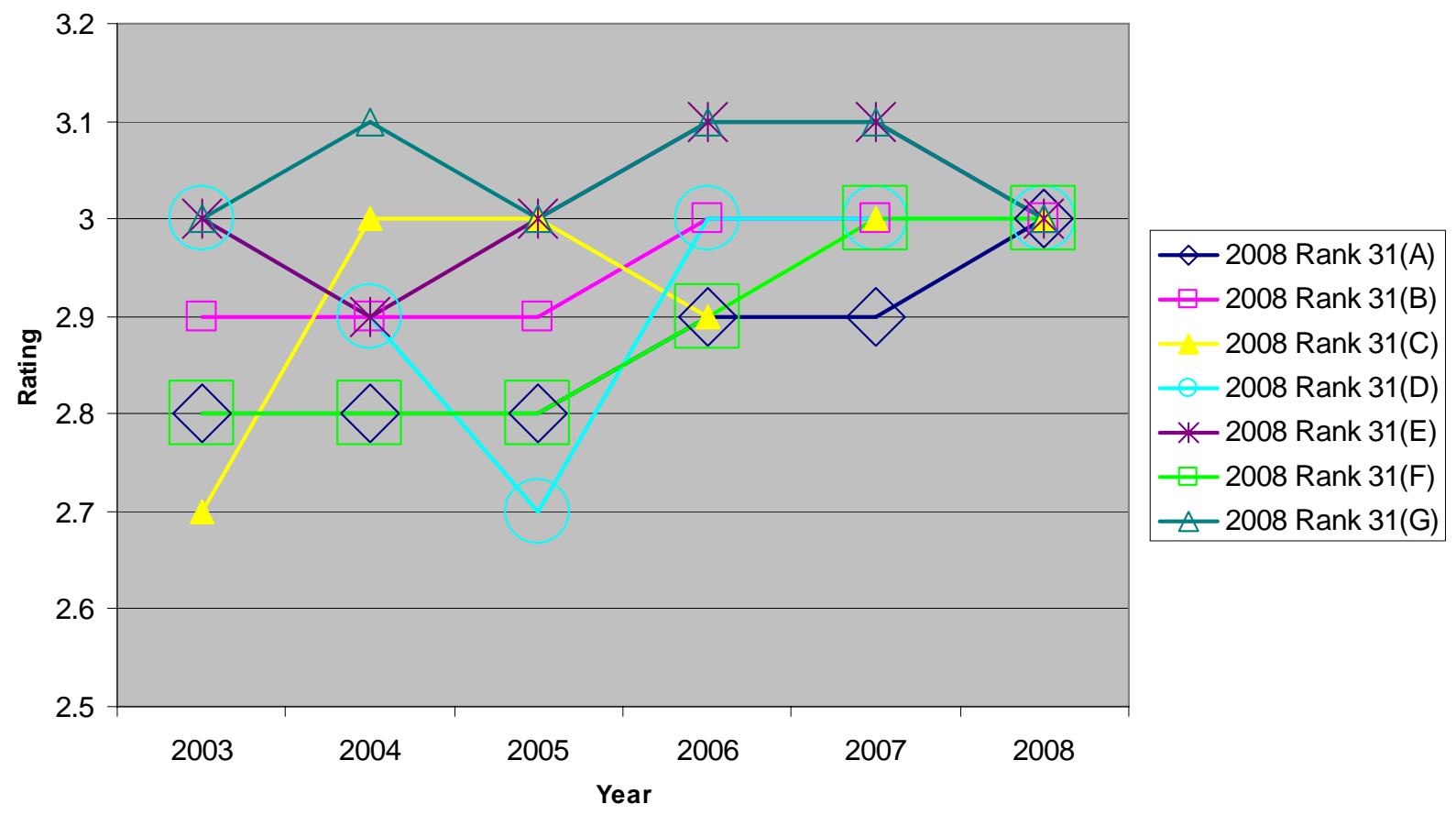

The two rightmost columns in Table 1 give the mean and standard deviation of the ratings over this six-year period. Figure 10 and Figure 11 present that information graphically. Figure 10 shows the Mean Ratings (blue) and Standard Deviations (red) for the 34 institutions that had ratings for the full six-year period. The highest mean rating, at 4.45, belongs to 2008 Rank 1(B), with three years at 4.4 and three years at 4.5. The previously noted high variations for 2008 Rank4 and 2008 Rank(16B) clearly show in the Standard Deviations (red) curve, with values of 0.20 and 0.18 , respectively, for the two institutions that had an 0.5 Rating variation (an increase) over this six-year period. But, altogether, the standard deviation seems modest compared to the ratings scale. Six programs share the smallest variation of 0.5 over this period.

Figure 11 shows the 2008 Ratings (red) together with the Mean Ratings (blue). An evident observation from Figure 11 is that the 2008 Ratings are modestly, but uniformly, higher than the Mean Ratings for the six-year period. 
Figure 10. Statistical Information (2003-2008 Ratings)

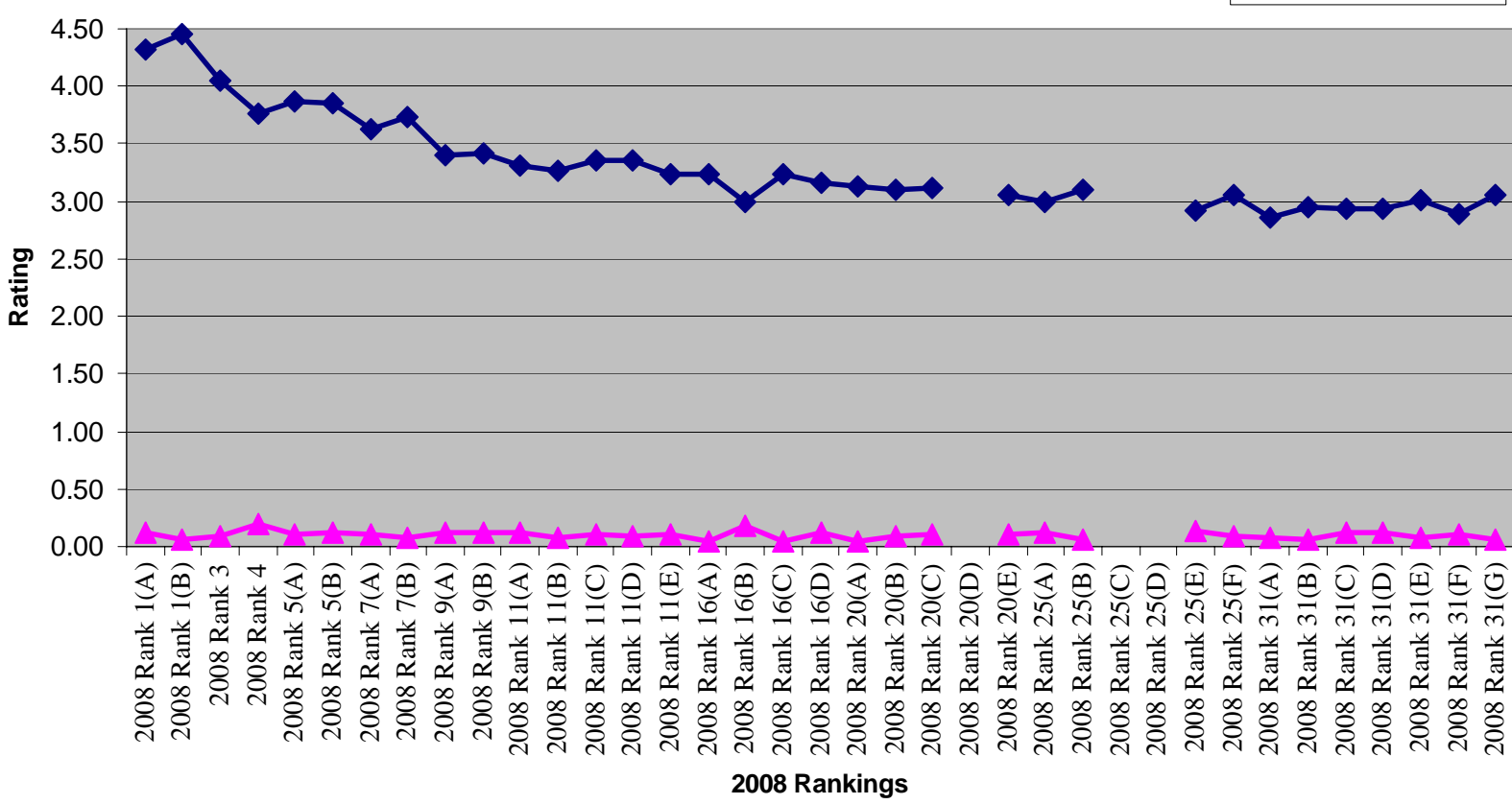

Figure 11. Statistical Information (2003-2008 Ratings)

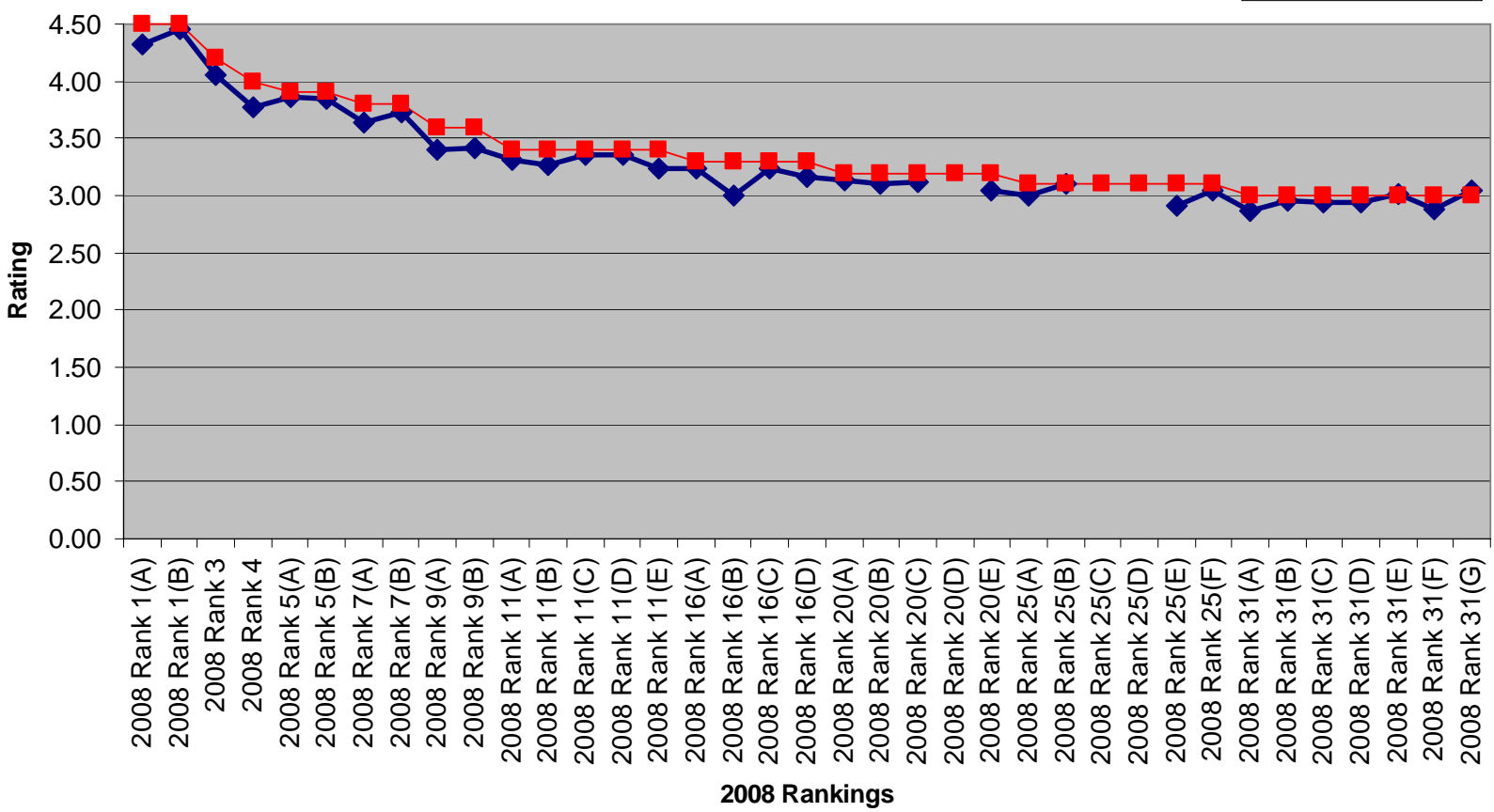

Proceedings of the 2008 ASEE Gulf-Southwest Annual Conference

The University of New Mexico - Albuquerque

Copyright ( 2008, American society for Engineering Education 


\section{Rankings}

While the ratings are the measured (or, at least, the original) data, the more commonly used information from this survey is the resulting rankings. While the rankings may provide a more understandable set of data for the general public, they can be no more accurate than the ratings from which they come. Given the relatively modest variation of the ratings in most cases, the next question is, statistically, "What do the more popularly used rankings reveal?"

Table 2 records the program ranking data that results from the corresponding rating data in Table 1 , together with the corresponding ranking statistics in the two rightmost columns. The programs have the same identification format as used for the preceding ratings analysis.

The 2008 Rankings for the 37 programs listed in Table 2 are shown in Figure 12, with the corresponding rankings from the two-way tie for first to the seven-way tie for thirty-first. The graph in Figure 12 and the subsequent respective Rankings graph groupings of programs in Figures 14-21 show the program rankings with the same sets of program groupings as Figures 29 did for program ratings. As noted previously for the Ratings graphs, the following Rankings graphs have a vertical scale with the "higher rankings" (lower numbers) appearing higher on the vertical scale. The most significant ranking issue, and the fundamental issue in the rating and ranking methodology is represented by the relative flatness of the Rankings graph in Figure 12

Figures 13-20 provide the program ranking data graphically for the six years (2003, 2004, 2005, 2006, 2007 and 2008) for equally ranked sets of these 37 programs, grouped according to the 2008 ranking, as follows:

Figure 13

Figure 14

Figure 15

Figure 16

Figure 17

Figure 18

Figure 19

Figure 20
2008 rankings 1 and 3

2008 rankings of 4 and 5

2008 rankings of 7 and 9

2008 rankings of 11

2008 rankings of 16

2008 rankings of 20

2008 rankings of 25

2008 rankings of 31
3 programs

3 programs

4 programs

5 programs

4 programs

5 programs

6 programs

7 programs

Figure 13 shows, again, that the program ranked second for several years rose to a tie in 2007 and 2008 with the program previously ranked alone at first for several preceding years. This simply reflects that their respective ratings converged (to within the ratings round-off to the nearest one decimal on the 1 to 5 rating scale). Comparing the Ratings in Figure 2 with the Rankings in Figure 13 for the top three programs suggests that the rankings are more stable than the ratings. However, the Rankings figures do not always support that conclusion.

Figure 14 shows that a program ranked ninth in 2003 has risen and indeed passed two programs, one of which had ranked five positions higher in 2003. Figure 15 shows that a program ranked fourth in 2003 fell to a tie for seventh in 2007. Figure 15 also shows a relative consistency of ranking from 2003 to 2008 for the other three programs (with maximum variation over that period of only two ranking levels). 
Table 2. US News Best Undergraduate Engineering Program Rankings

\begin{tabular}{|c|c|c|c|c|c|c|c|c|}
\hline & 2003 & 2004 & 2005 & 2006 & 2007 & 2008 & Mean & STD1 \\
\hline 2008 Rank 1(A) & 2 & 2 & 2 & 2 & 1 & 1 & 1.67 & 0.52 \\
\hline 2008 Rank 1(B) & 1 & 1 & 1 & 1 & 1 & 1 & 1.00 & 0.00 \\
\hline 2008 Rank 3 & 3 & 3 & 3 & 3 & 3 & 3 & 3.00 & 0.00 \\
\hline 2008 Rank 4 & 9 & 6 & 6 & 4 & 6 & 4 & 5.83 & 1.83 \\
\hline 2008 Rank 5(A) & 4 & 4 & 4 & 4 & 3 & 5 & 4.00 & 0.63 \\
\hline 2008 Rank 5(B) & 6 & 4 & 4 & 4 & 3 & 5 & 4.33 & 1.03 \\
\hline 2008 Rank 7(A) & 8 & 8 & 8 & 8 & 7 & 7 & 7.67 & 0.52 \\
\hline 2008 Rank 7(B) & 4 & 6 & 6 & 7 & 7 & 7 & 6.17 & 1.17 \\
\hline 2008 Rank 9(A) & 10 & 9 & 10 & 11 & 9 & 9 & 9.67 & 0.82 \\
\hline 2008 Rank 9(B) & 10 & 9 & 9 & 11 & 9 & 9 & 9.50 & 0.84 \\
\hline 2008 Rank 11(A) & 10 & 14 & 14 & 9 & 12 & 11 & 11.67 & 2.07 \\
\hline 2008 Rank 11(B) & 16 & 14 & 10 & 14 & 12 & 11 & 12.83 & 2.23 \\
\hline 2008 Rank 11(C) & 10 & 9 & 14 & 11 & 9 & 11 & 10.67 & 1.86 \\
\hline 2008 Rank 11(D) & 10 & 9 & 10 & 9 & 12 & 11 & 10.17 & 1.17 \\
\hline 2008 Rank 11(E) & 16 & 19 & 10 & 14 & 16 & 11 & 14.33 & 3.39 \\
\hline 2008 Rank 16(A) & 16 & 9 & 14 & 14 & 16 & 16 & 14.17 & 2.71 \\
\hline 2008 Rank 16(B) & 36 & 27 & 21 & 32 & 20 & 16 & 25.33 & 7.69 \\
\hline 2008 Rank 16(C) & 16 & 14 & 14 & 14 & 12 & 16 & 14.33 & 1.51 \\
\hline 2008 Rank 16(D) & 10 & 14 & 21 & 21 & 20 & 16 & 17.00 & 4.47 \\
\hline 2008 Rank 20(A) & 20 & 19 & 14 & 21 & 20 & 20 & 19.00 & 2.53 \\
\hline 2008 Rank 20(B) & 20 & 14 & 21 & 29 & 20 & 20 & 20.67 & 4.80 \\
\hline 2008 Rank 20(C) & 20 & 22 & 21 & 14 & 16 & 20 & 18.83 & 3.13 \\
\hline 2008 Rank 20(D) & & & & 14 & 29 & 20 & & \\
\hline 2008 Rank 20(E) & 25 & 27 & 21 & 21 & 20 & 20 & 22.33 & 2.94 \\
\hline 2008 Rank 25(A) & 30 & 33 & 21 & 21 & 20 & 25 & 25.00 & 5.40 \\
\hline 2008 Rank 25(B) & 20 & 22 & 19 & 14 & 20 & 25 & 20.00 & 3.63 \\
\hline 2008 Rank 25(C) & & & & & 36 & 25 & & \\
\hline 2008 Rank 25(D) & & & & 21 & 16 & 25 & & \\
\hline 2008 Rank 25(E) & 30 & 40 & 30 & 32 & 29 & 25 & 31.00 & 4.98 \\
\hline 2008 Rank 25(F) & 20 & 22 & 19 & 21 & 36 & 25 & 23.83 & 6.31 \\
\hline 2008 Rank 31(A) & 36 & 33 & 33 & 32 & 36 & 31 & 33.50 & 2.07 \\
\hline 2008 Rank 31(B) & 30 & 27 & 30 & 29 & 29 & 31 & 29.33 & 1.37 \\
\hline 2008 Rank 31(C) & 46 & 22 & 21 & 32 & 29 & 31 & 30.17 & 9.02 \\
\hline 2008 Rank 31(D) & 25 & 27 & 39 & 29 & 29 & 31 & 30.00 & 4.86 \\
\hline 2008 Rank 31(E) & 25 & 27 & 21 & 21 & 20 & 31 & 24.17 & 4.31 \\
\hline 2008 Rank 31(F) & 36 & 33 & 33 & 32 & 29 & 31 & 32.33 & 2.34 \\
\hline 2008 Rank 31(G) & 25 & 19 & 21 & 21 & 20 & 31 & 22.83 & 4.49 \\
\hline
\end{tabular}


Figure 12. 2008 Rankings

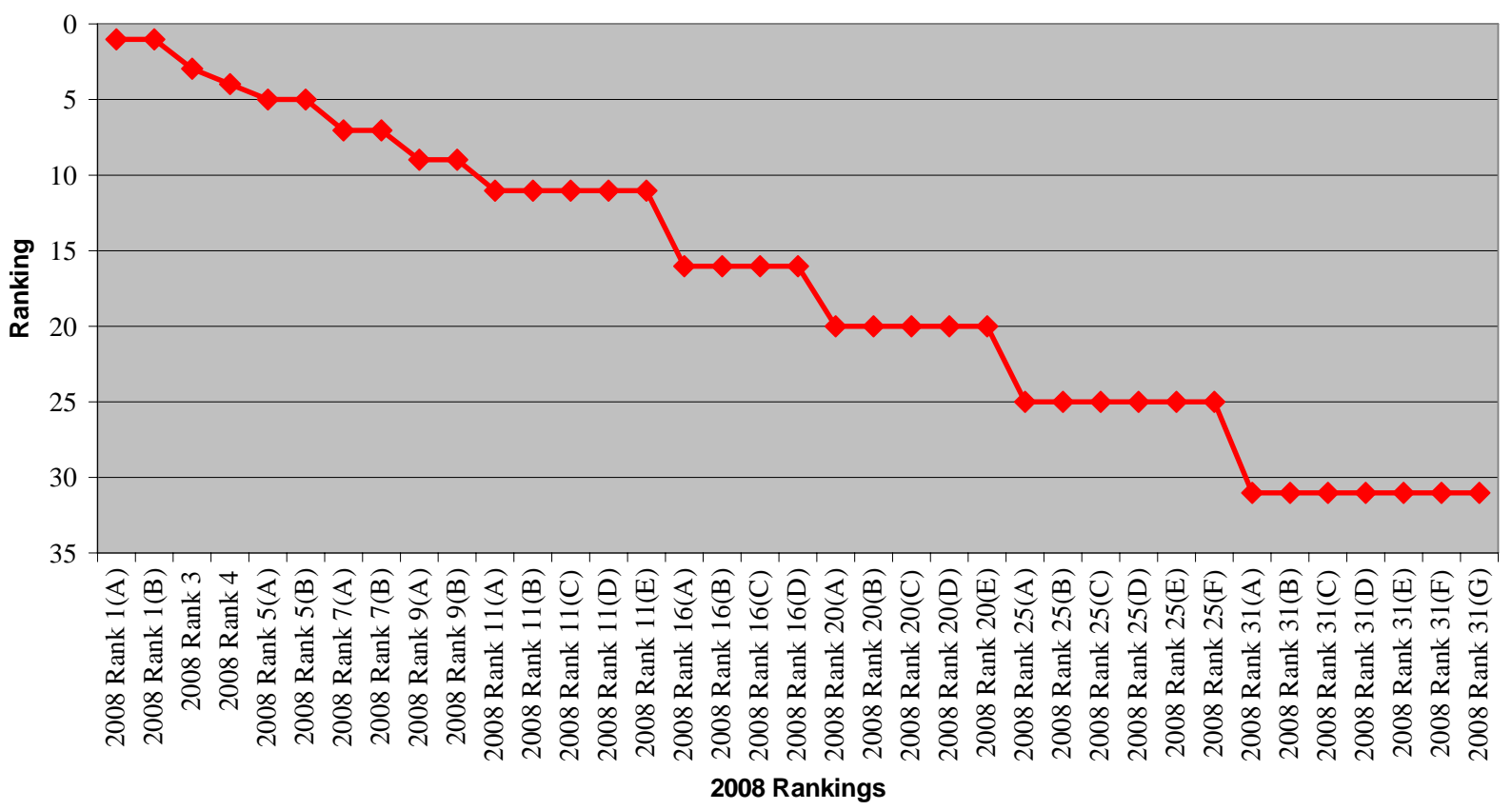

However, as subsequent figures reveal, relative consistency is largely limited to the top ten or so programs. Figure 16, showing five programs tied for rank eleven in 2008, includes programs with variations of nine, six, five, five, and three positions (as high as ninth and as low as nineteenth) before arriving at a tie at eleven in 2008. Figure 17 shows the four programs tied for sixteenth in 2008, with variations over the six years from as high as ninth and as low as thirtysixth. One of those programs rose from thirty-sixth in 2003 to the tie for sixteenth in 2008. That program had received ratings that increased from 2.8 to 3.3 over that same period. Another fell from ninth to the tie for sixteenth over that period. Another started at tenth, fell to 21, and then came back to 16. Both Figure 18 and Figure 19 show remarkable up-and-down variation over the six years. The greatest ranking change appears in Figure 20, with one program climbing from forty-sixth to twenty-first over a two-year period, before settling into the twenty-ninth to thirty-second range for the past three years.

Corresponding to the mean Rating and Standard Deviation statistics shown in Figure 10, Figure 21 shows the mean Ranking and Standard Deviation for these 37 programs over this six-year period. While the Rating Standard Deviation shown in Figure 10 remained relatively uniform over the Rating range, the Ranking Standard Deviation shown in Figure 21 increases markedly for the lower Rankings. Similar perspective is given by Figure 11 and Figure 22. Interestingly, while the mean Ratings in Figure 11 were consistently below the 2008 Ratings, the mean Rankings in Figure 22 do not follow a more diverse pattern. The 2008 Rating graph in Figure 1 and the 2008 Ranking graph in Figure 12, show the increasing volatility of the "lower rating numbers/higher ranking numbers" programs, due to the relative flatness of the respective curves and especially the precisely flat portions. 
Figure 13. 2003-2008 Rankings (2008 Rank 1(A)-3)

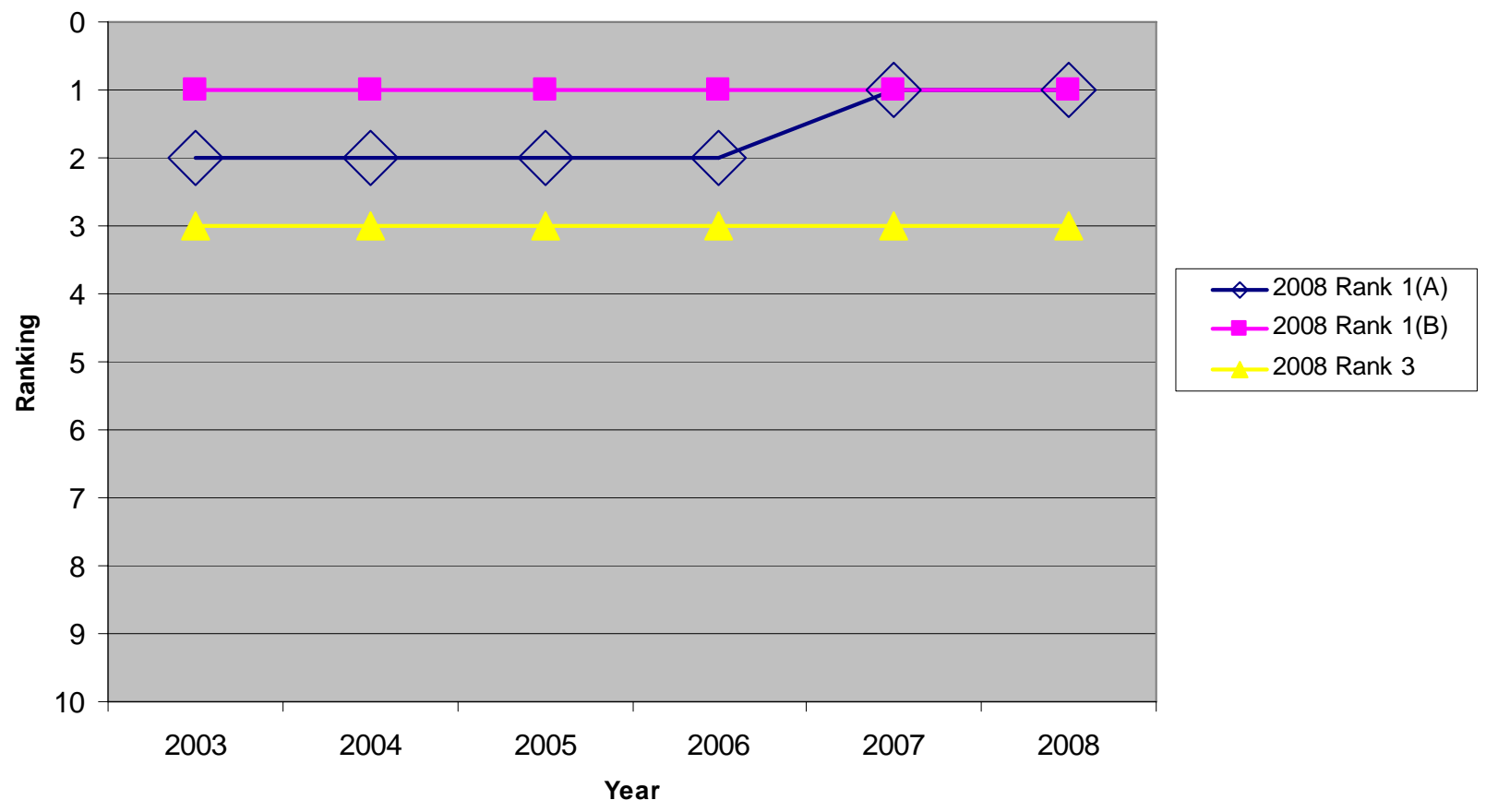

Figure 14. 2003-2008 Rankings (2008 Rank 4-5(B))

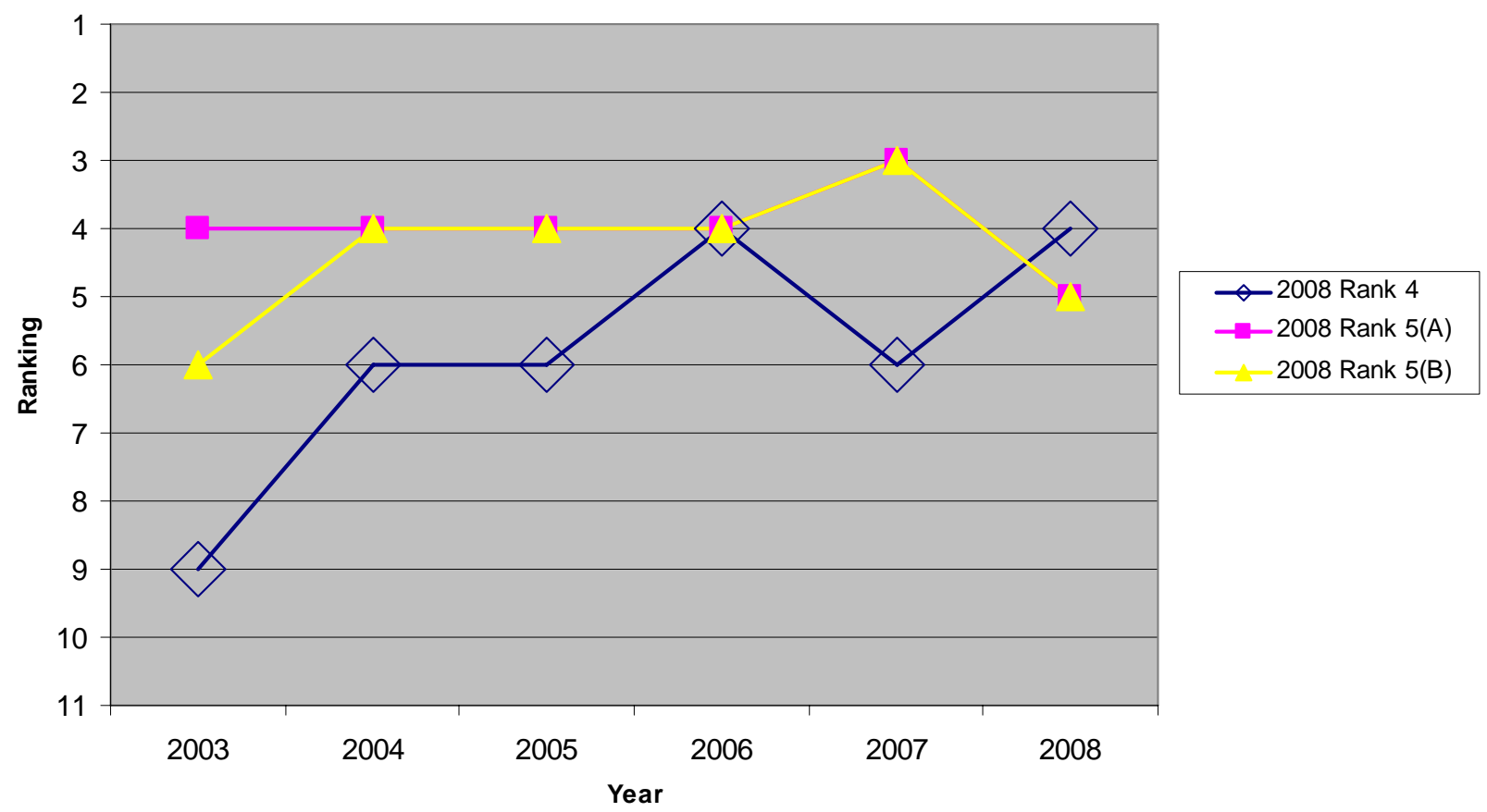

Proceedings of the 2008 ASEE Gulf-Southwest Annual Conference The University of New Mexico - Albuquerque

Copyright (C) 2008, American society for Engineering Education 
Figure 15. 2003-2008 Rankings (2008 Rank 7(A)-9(B))
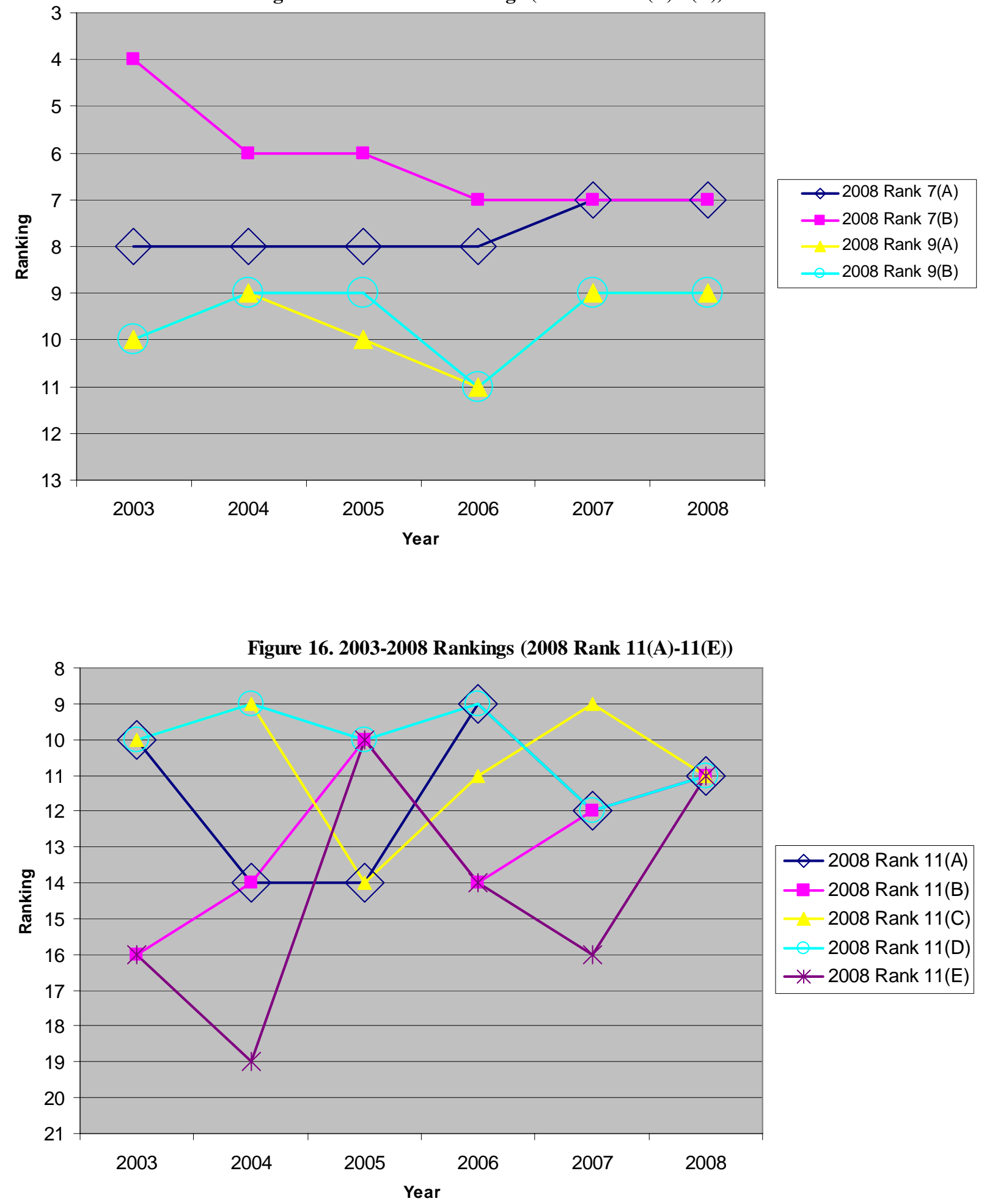

Proceedings of the 2008 ASEE Gulf-Southwest Annual Conference The University of New Mexico - Albuquerque

Copyright $₫$ 2008, American society for Engineering Education 
Figure 17. 2003-2008 Rankings (2008 Rank 16(A)-16(D))

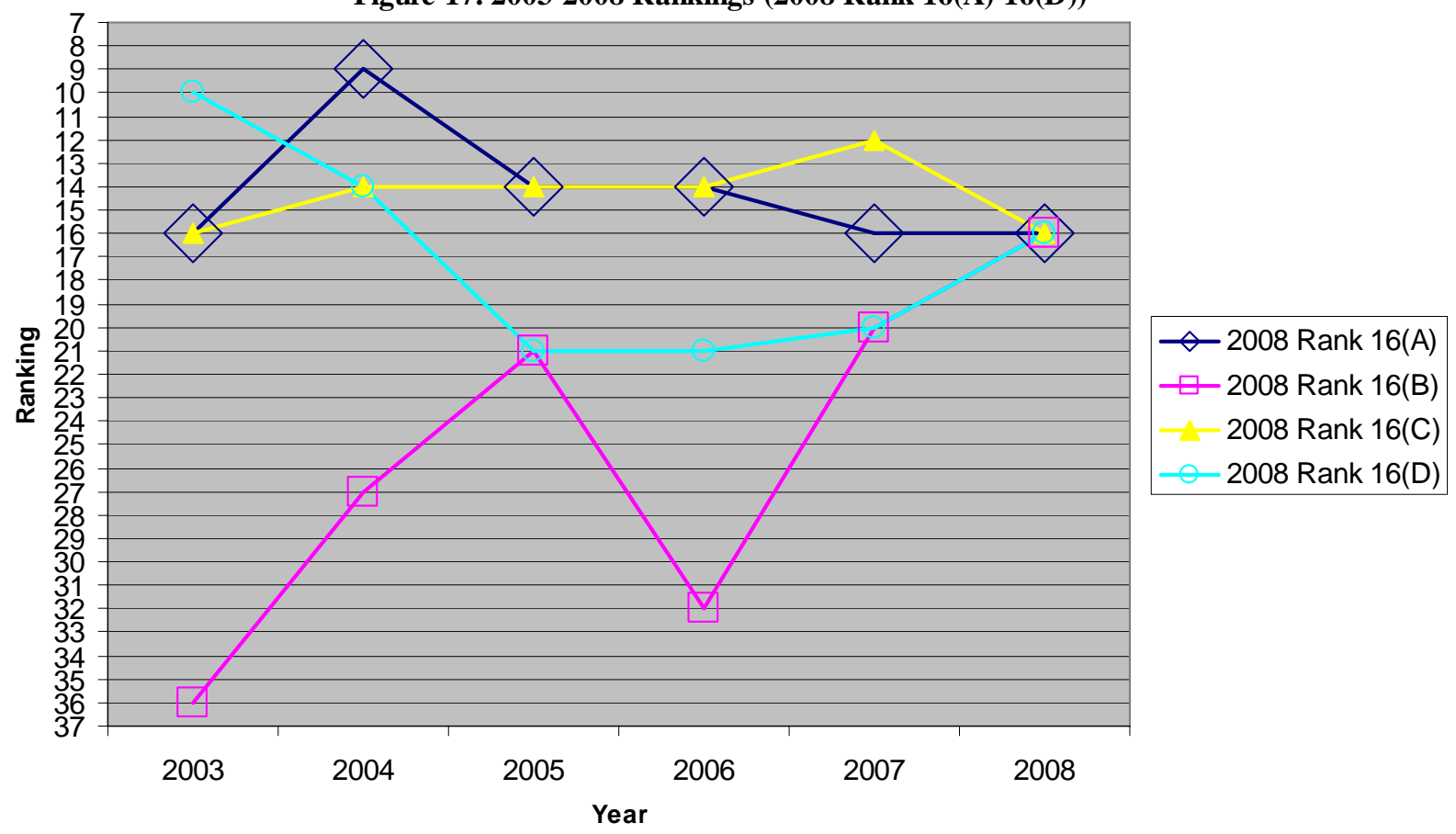

Figure 18. 2003-2008 Rankings (2008 Rank 20(A)-20(E))

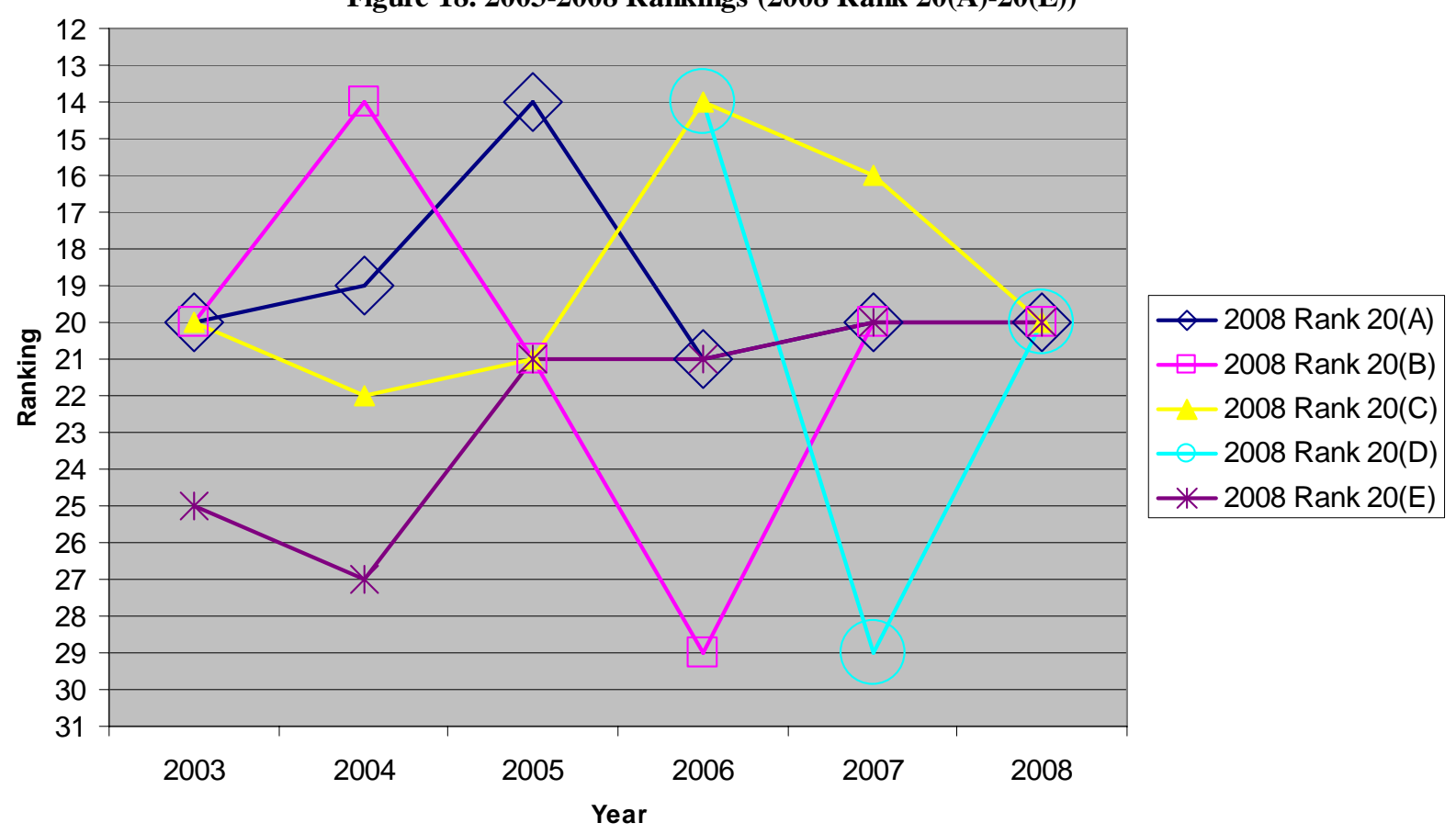

Proceedings of the 2008 ASEE Gulf-Southwest Annual Conference The University of New Mexico - Albuquerque

Copyright ( ${ }^{2}$ 2008, American society for Engineering Education 
Figure 19. 2003-2008 Rankings (2008 Rank 25(A)-25(F))

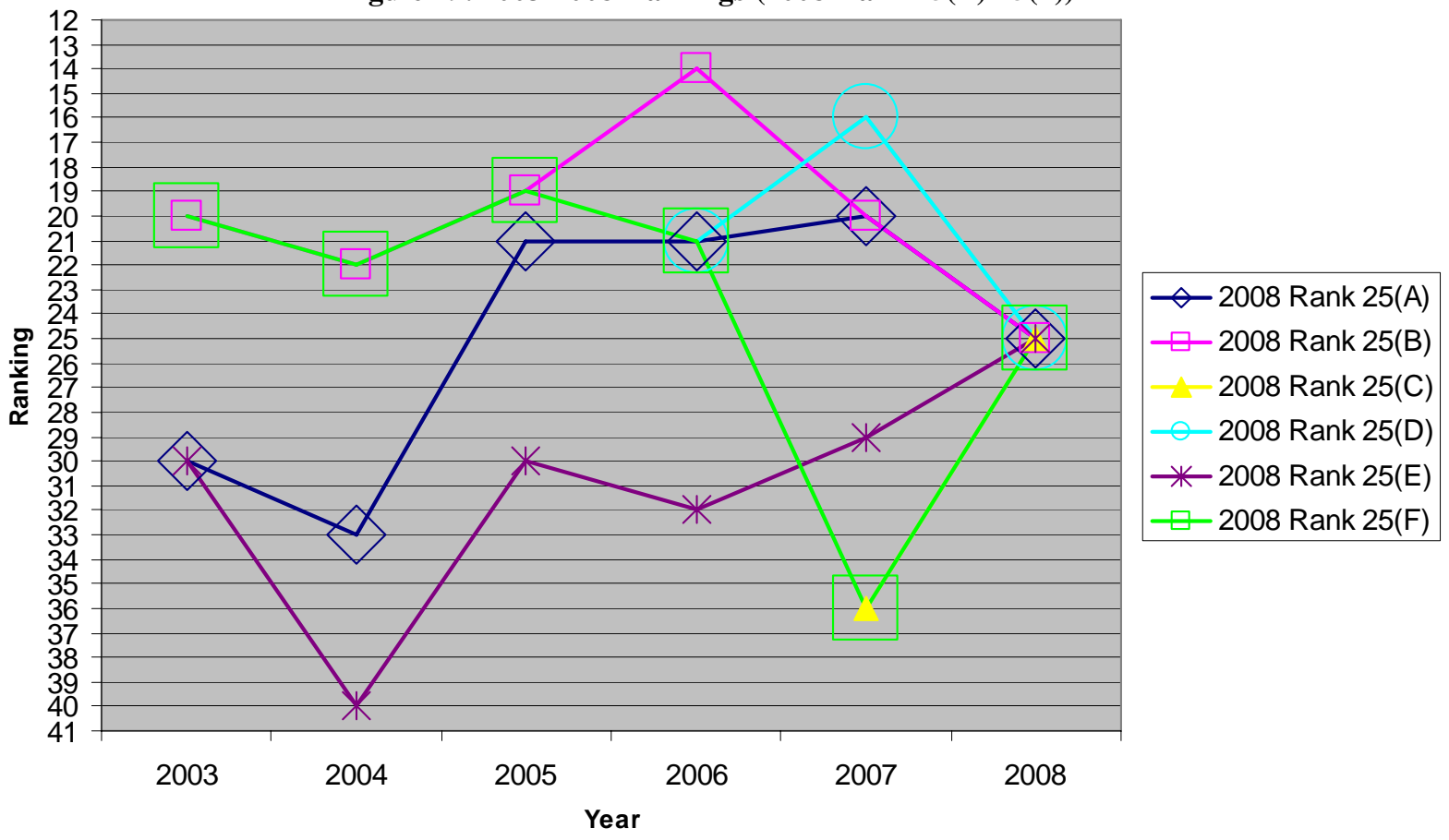

Figure 20. 2003-2008 Rankings (2008 Rank 31(A)-31(G))

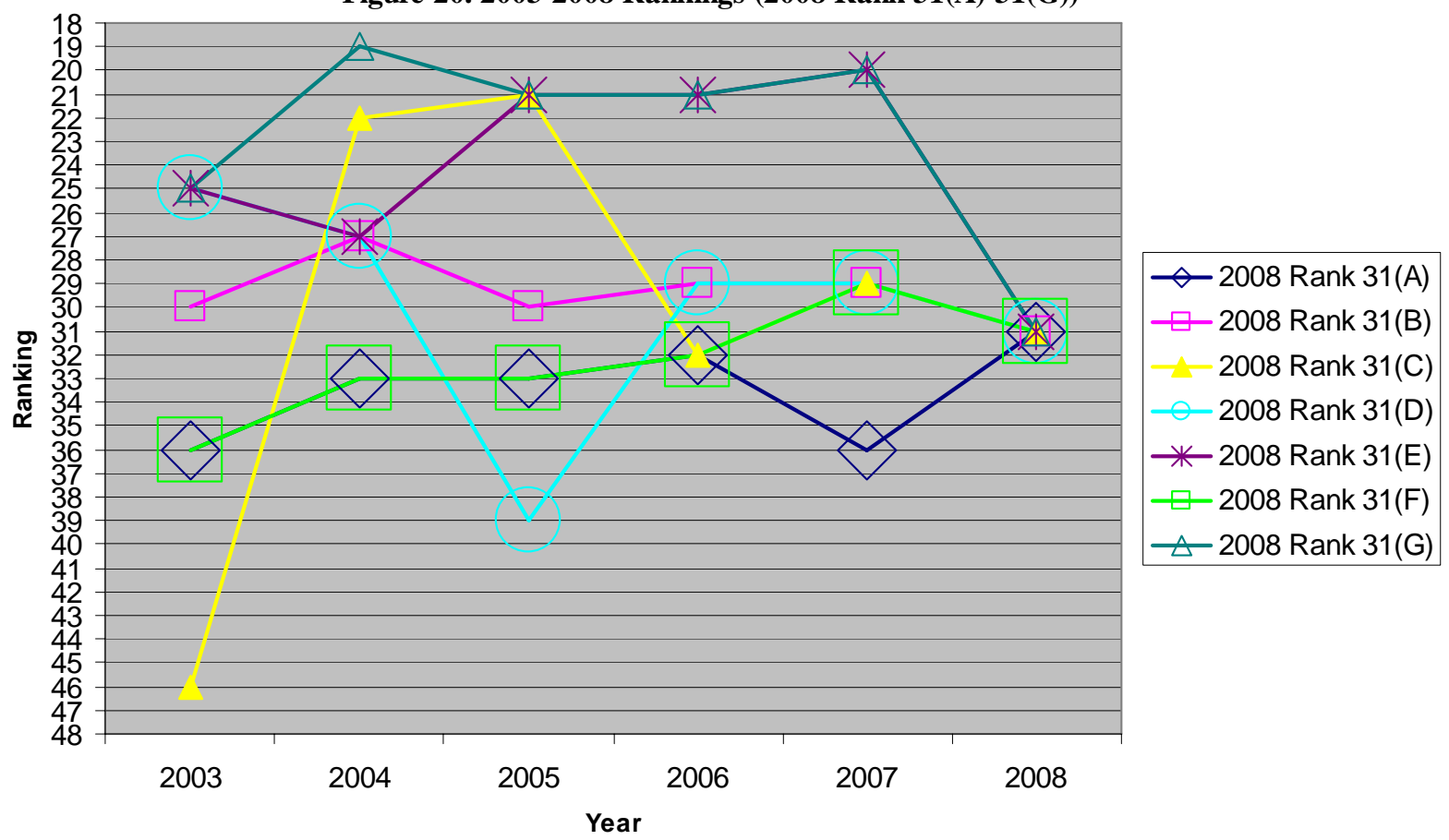

Proceedings of the 2008 ASEE Gulf-Southwest Annual Conference The University of New Mexico - Albuquerque

Copyright $(0) 2008$, American society for Engineering Education 


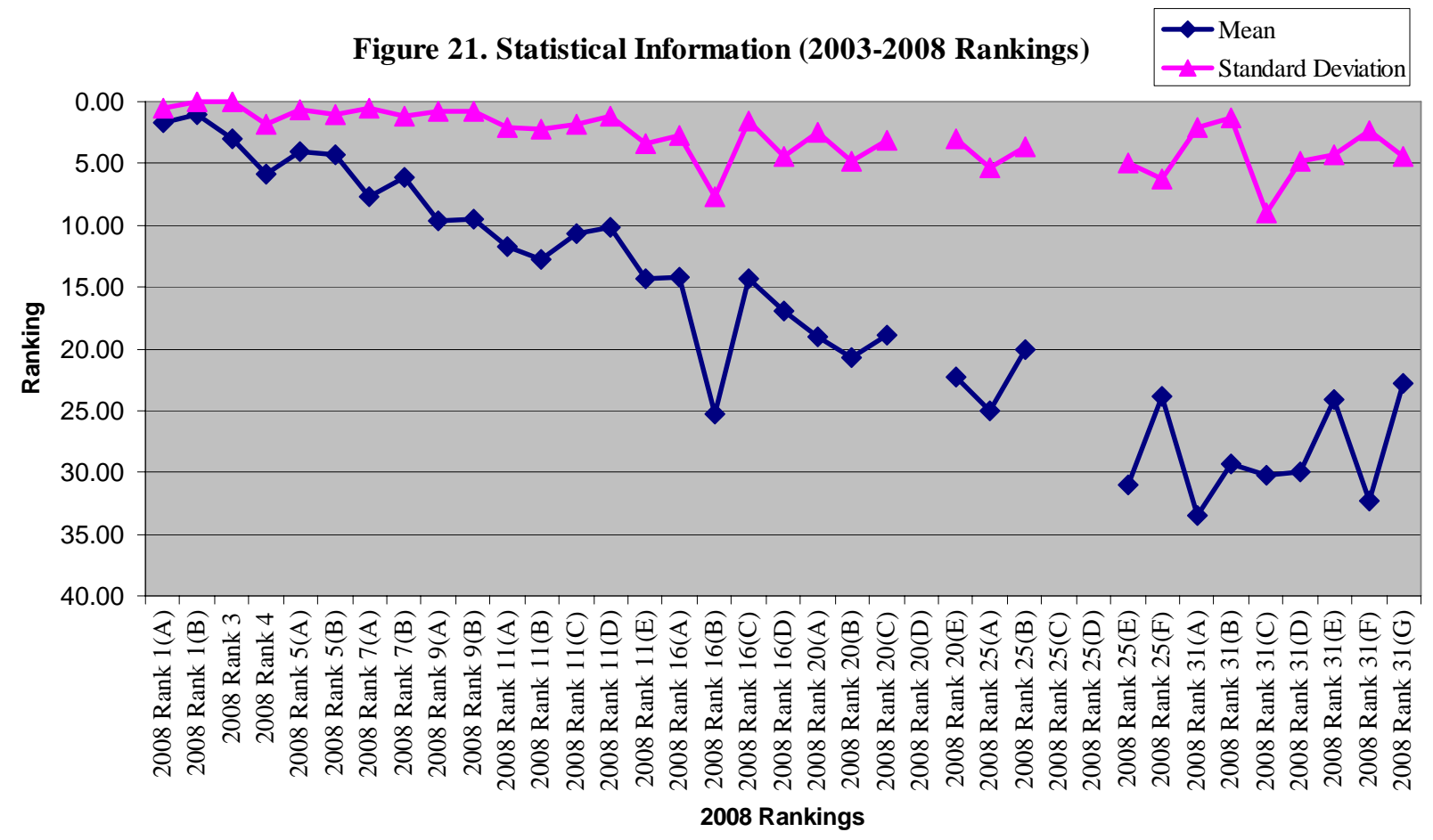

Figure 22. Statistical Information (2003-2008 Rankings)

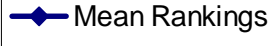
2008 Rankings

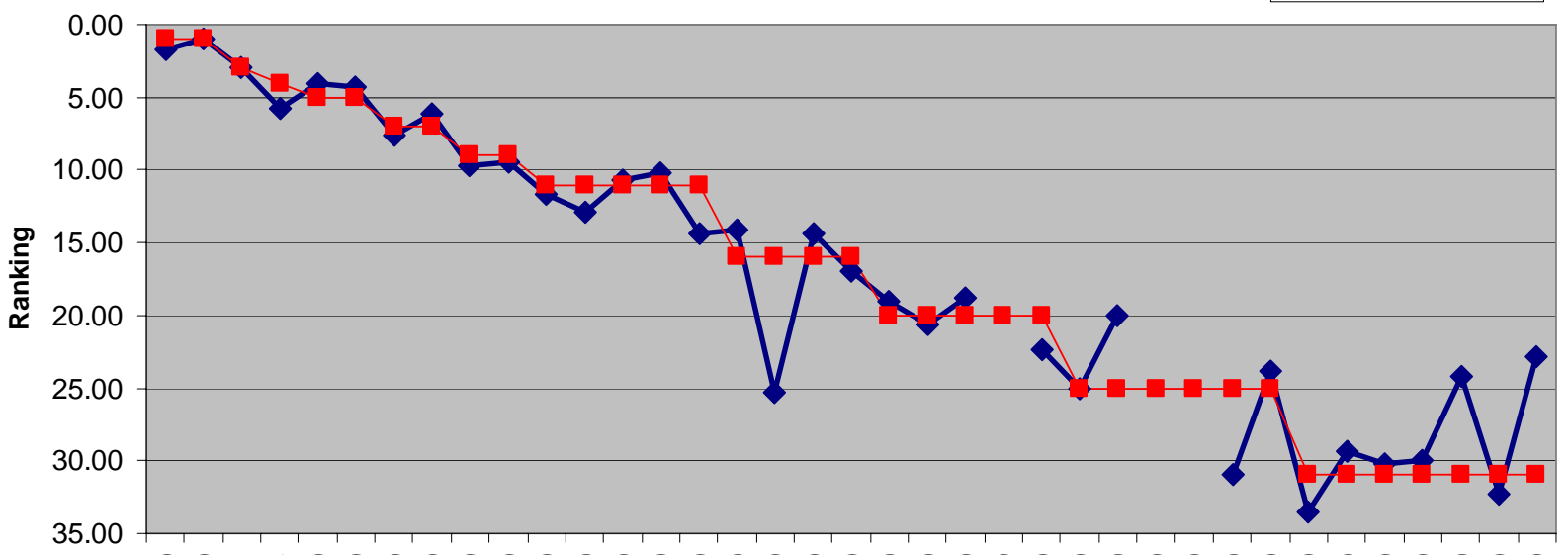

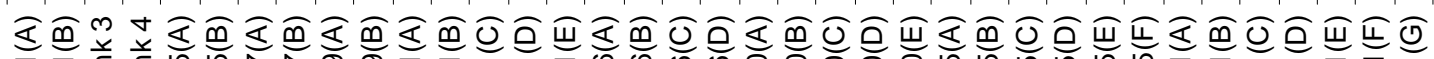

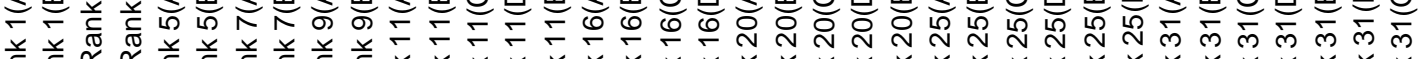
空

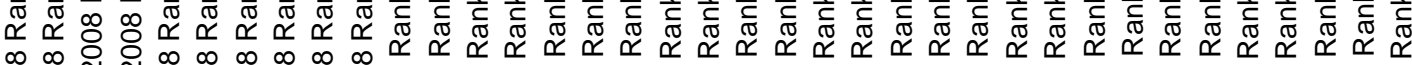

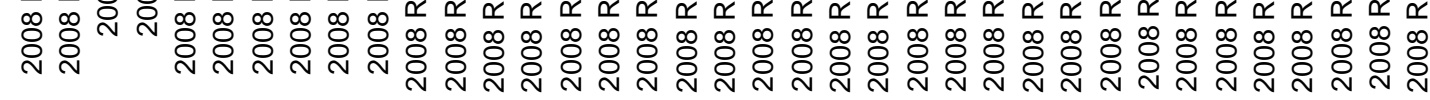




\section{Summary}

The annual U.S. News ranking of engineering programs in institutions without doctoral programs in engineering, based as they are on the individual ratings from 1 to 5 by engineering educators/ administrators, are interesting and likely have some validity. On the other hand, the analysis presented in this paper documents the variability of those ratings and, especially, the rankings from year to year and provides some indications of the degree of variability from year to year. It seems reasonable to believe that this annual ranking variation is very likely due more to the survey procedure than to significant changes in the quality of the respective programs.

With its survey methodology of determining these ratings and assuming that most of these programs would not vary significantly from year to year, one could reasonably conjecture that most of these ratings should be relatively consistent from year to year--with some modest variation over time and an occasional stronger pattern of change that might in fact be based in some objective cause (winning some national competition, receiving some well publicized award, some serious negative event, etc.). But, without further research, even this remains at most a conjecture.

And, as U.S. News says elsewhere on their web site, "Don't rely solely on rankings to choose a college.”

\section{References}

1. Jim Farison, "Some characteristics of highly ranked programs in the U.S. News \& World Report ranking of engineering programs in institutions without doctoral programs," ASEE Annual Conference \& Exhibition Proceedings (12 pages), Portland, Oregon, June 12-15, 2005.

2. Jim Farison and Carmen LiShen, "Longitudinal Study of U.S. News Rankings of Engineering Programs in Institutions without Doctoral Programs in Engineering,” ASEE Annual Conference \& Exhibition Proceedings (18 pages), Chicago, IL, June 18-21, 2006.

3. http://colleges.usnews.rankingsandreviews.com/usnews/edu/college/rankings/about/engmeth brief.php, U. S. News web site, accessed February 7, 2008.

\section{JAMES B. FARISON}

Dr. Farison is a professor in Baylor's ECE department, and also coordinates Baylor's interdepartmental, multidisciplinary Engineering major. He holds M.S./Ph.D. in EE from Stanford U., and served over 34 years at the U. Toledo, OH, including 10 years as Engrg. Dean. He is an ASEE Fellow, ASEE Accreditation Activities Committee member, ASEE Multidisciplinary Engineering Division past chair, Baylor's ASEE campus rep, and PE in OH, TX.

\section{ZHUOCHENG YANG}

Mr. Yang received his Bachelor of Science degree in Electrical Engineering from Donghua University, Shanghai, China, in 2006, and is currently a graduate student in the Department of Electrical and Computer Engineering at Baylor University. He has previously worked in applications of image processing, and expects to conduct his master thesis research in that area. 